\title{
What's right with my mouse model? New insights into the molecular and cellular basis of cognition from mouse models of Rubinstein-Taybi Syndrome
}

\author{
Sheena A. Josselyn \\ Program in Integrative Biology and Brain \& Behaviour, Hospital for Sick Children Research Institute, Toronto, \\ Ontario, Canada, M5G 1X8, and Department of Physiology, University of Toronto, Toronto, Ontario, Canada M5G 1 X8
}

The first gene-targeting studies that examined learning and memory in mice were performed in 1992 (Grant et al. 1992; Silva et al. 1992). The ultimate goal of this new field was to understand the molecular and cellular processes underlying normal cognition and how they may be altered in disease states. In the years since these pioneering studies, well over 100 different molecules have been identified that are essential to or modulate learning and memory. Despite this rapid progress, the translation of these basic findings to human cognitive disorders has been slow. However, this may be changing. In this issue, Wood et al. (2005) use a combination of approaches to examine the molecular, cellular, and systems basis of a learning and memory disorder. Together with recent results from other groups, these findings not only provide valuable insights into cognition, but represent important first steps toward developing treatments for cognitive disorders.

Rubinstein-Taybi syndrome (RTS) is a human genetic disorder characterized by mental retardation and physical abnormalities. RTS is caused by chromosomal rearrangements, microdeletions, and point mutations in one copy of the gene encoding CREB-binding protein (CBP) (Petrij et al. 1995). CBP is a multidomain protein that serves as an essential transcription coactivator for many transcription factors such as CREB, c-Jun and c-Fos (Chrivia et al. 1993). It is thought that CBP facilitates transcription by coupling transcription-factor recognition to chromatin remodeling (McManus et al. 2001). First, CBP serves as a physical link between DNA-binding transcription factors and the basal transcriptional machinery. Second, CBP facilitates transcription through intrinsic histone acetyltransferase (HAT) activity that opens up condensed DNA, thereby allowing the transcriptional machinery greater access.

CBP was first identified by its ability to interact with an activated (phosphorylated at Ser133) form of CREB (Chrivia et al. 1993). Numerous studies from invertebrate and vertebrate species implicate CREB-mediated transcription in memory and synaptic plasticity (Dash et al. 1990; Bourtchuladze et al. 1994; Yin et al. 1994; Bartsch et al. 1995; Josselyn et al. 2001; Kida et al. 2002). These findings led to the notion that disruption of CREB:CBP function contributes to the cognitive dysfunction observed in patients with RTS.

Soon after the gene responsible for RTS was identified, two mouse models of RTS were generated. The first model is a conventional knockout with a heterozygous null mutation of CBP $\left(\mathrm{CBP}^{+/-}\right)$(Tanaka et al. 1997). The second model has an insertional mutation in one $c b p$ allele that produces CBP protein with a C-terminal truncation (CBP $\left.{ }^{+/-C-t e r m}\right)$ (Oike et al. 1999). This truncated protein lacks the HAT domain and may function as a dominant negative. Mice homozygous for either of these germ-

E-mail sheena.josselyn@sickkids.ca; fax (416) 813-6846.

Article and publication are at http://www.learnmem.org/cgi/doi/10.1101/ Im.93505. line mutations die prenatally, indicating that CBP performs vital developmental functions. However, heterozygous mice are viable and show phenotypic overlap with RTS patients, including skeletal and cardiac abnormalities, growth retardation, and memory deficits (Tanaka et al. 1997; Oike et al. 1999; Alarcón et al. 2004) (see Table 1). In both of these mouse models, however, CBP function is compromised throughout development and throughout the body. Therefore, the possible contributions of CBP to adult memory processes cannot be adequately assessed.

To directly determine the effects of disrupting CBP function on synaptic plasticity and memory in adult brains, Wood et al. (2005) developed transgenic mice in which a truncated form of $\mathrm{CBP}(\mathrm{CBP} \Delta 1)$ is expressed only in postnatal forebrain neurons. The truncated form of $\mathrm{CBP}$ retains the $\mathrm{N}$ terminus (including the binding site for a subset of transcription factors that normally bind to CBP, such as CREB) but lacks the $\mathrm{C}$ terminus of fulllength CBP (including the HAT domain that is important for chromatin remodeling and transcriptional activation). Therefore, this truncated protein should disrupt the function of a subset of CBP-binding transcription factors. To test this, these researchers used cell cultures and hippocampal microarrays. Wood et al. (2005) observed that CBP $\Delta 1$ does not impair the basal transcription of several "housekeeping genes", but severely disrupts gene expression normally induced by CREB activation. Importantly, this finding is in keeping with results showing that mutations of the CBP HAT domain in several RTS cases are associated with marked impairments in CREB-mediated transcription (Kalkhoven et al. 2003). To direct expression of CBP 1 to postnatal excitatory neurons in the forebrain (including the hippocampus, cortex, and amygdala), the transgene was placed under the control of the $\alpha$ CaMKII promoter. The resulting CBP $\Delta 1$ transgenic mice appear free from developmental abnormalities and have normal weight, locomotor activity, and anxiety levels.

Wood et al. (2005) assessed the effects of overexpressing the truncated form of CBP on short- and long-term memory using a fear-conditioning paradigm. In this task, an aversive footshock is delivered following placement in a novel chamber (contextual fear conditioning) or delivery of a tone (cued fear conditioning). Contextual fear conditioning involves both the hippocampus and amygdala, while cued fear conditioning critically involves the amygdala (Fanselow 2000; LeDoux 2000). CBP $\Delta 1$ transgenic mice show a specific deficit in long-term memory (LTM), but intact short-term memory (STM), following contextual fear conditioning. This result agrees with extensive evidence that LTM, but not STM, requires the transcription and translation of new proteins (Davis and Squire 1984; Matthies 1989). Perhaps surprisingly, no impairment was observed following cued fear conditioning. The authors hypothesize that this may be due to lower expression of CBP $\Delta 1$ in the amygdala of these transgenic mice or differences between the sensitivity of the amygdala and hippocampus to disruptions of CBP function. 

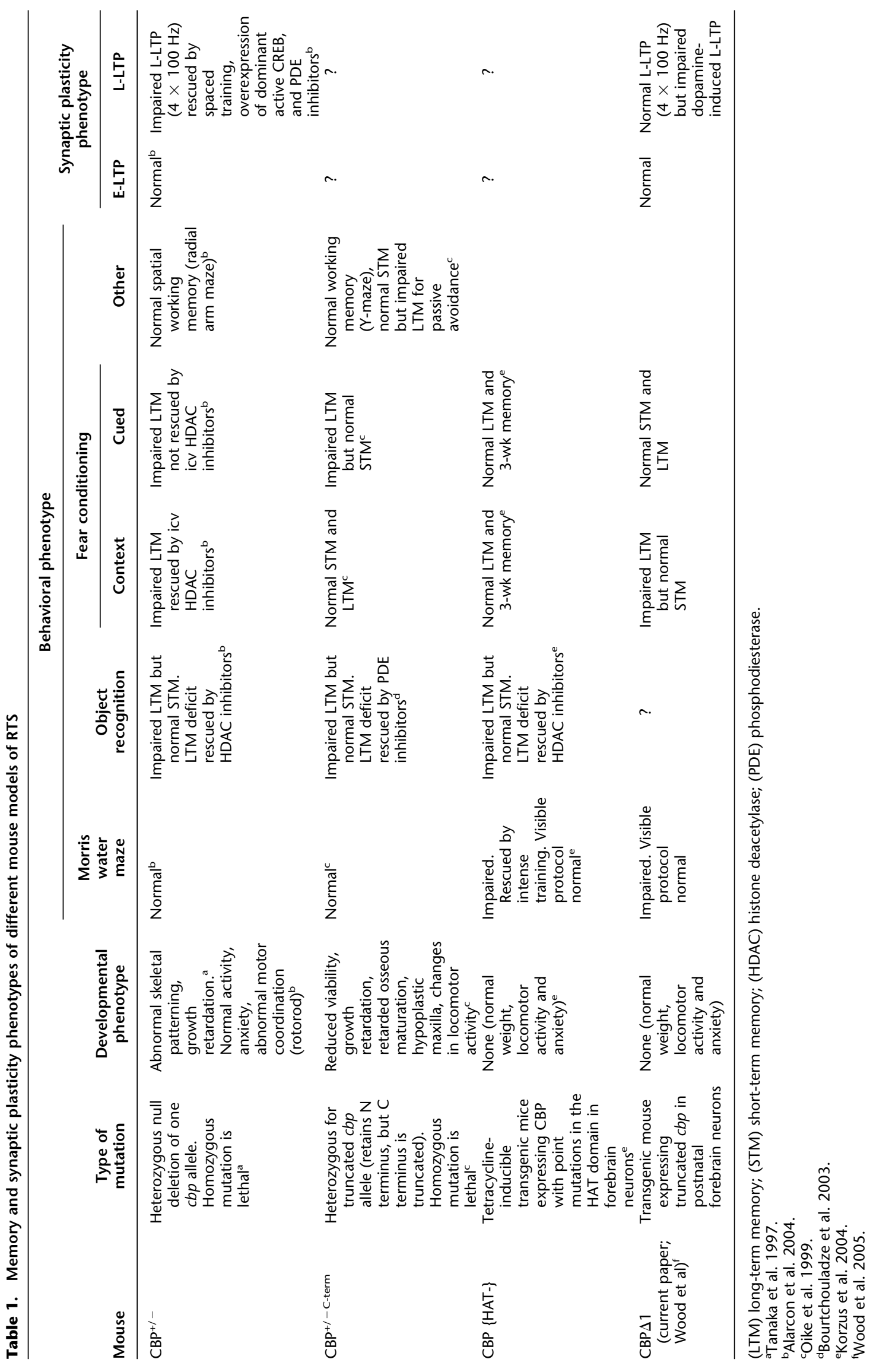
To assess hippocampal-dependent spatial memory, Wood and colleagues turned to the Morris water maze. Following $10 \mathrm{~d}$ of training, CBP $\Delta 1$ transgenic mice show severe deficits in spatial memory. Importantly, these transgenic mice performed normally on a hippocampal-independent version of this task (using a visible platform), indicating that the motor abilities and motivational aspects required to perform this task are intact in these mice. Therefore, Wood and colleagues demonstrate that CBP function in adult neurons is critically required for the formation of hippocampal-dependent memory. These results are in general agreement with the memory deficits observed in another type of $\mathrm{CBP}$ transgenic mouse (CBP $\left.\left\{\mathrm{HAT}^{-}\right\}\right)$(Korzus et al. 2004). $\mathrm{CBP}\left\{\mathrm{HAT}^{-}\right\}$transgenic mice express full-length $\mathrm{CBP}$ with two point mutations that abolish HAT activity in adult forebrain neurons following administration of doxycycline. Activation of this dominant-negative CBP impaired two types of hippocampaldependent memory (spatial memory and object recognition), but spared fear-conditioning memory (Korzus et al. 2004).

Having observed that the transgenic mice show impairments in two types of hippocampal-dependent memory, Wood et al. (2005) next examined the effects of CBP 1 on the synaptic plasticity hypothesized to be involved in hippocampaldependent memory. To comprehensively examine this phenotype, Wood and colleagues used a number of different protocols to induce to long-term potentiation (LTP) in the CA1 region of the hippocampus. Similar to memory, LTP consists of distinct phases that differentially require transcription; early phases of LTP (E-LTP) do not require transcription, whereas late phases of LTP (L-LTP) do. Both E-LTP (produced by a single train of $100 \mathrm{~Hz}$ stimulation) and tetraburst-induced L-LTP (produced by $4 \times 100$ $\mathrm{Hz}$ stimulation) are normal in CBP 1 transgenic mice. In contrast, dopamine agonist-induced L-LTP is severely impaired. These results represent the first demonstration that intact CBP function in adult neurons is required for some forms of synaptic plasticity.

It is interesting to note the striking similarity between the LTP phenotype Wood and colleagues observed in CBP 1 transgenic mice and that observed in transgenic mice expressing a dominant-negative form of CREB (K-CREB) (Pittenger et al. 2002). Both mutants show intact tetraburst L-LTP, but impaired dopamine agonist-induced L-LTP. This parallel suggests that although CBP serves as a cofactor for several transcription factors, the CREB:CBP interaction may be critical for synaptic plasticity. This notion is bolstered by recent findings showing that increasing CREB function can at least partially ameliorate the plasticity deficits observed in two mouse models of RTS. First, Bourtchouladze and colleagues rescued the impairment of object recognition LTM in mice with one truncated $c b p$ allele $\left(\mathrm{CBP}^{+/-\mathrm{C} \text {-term })}\right.$ with several phosphodiesterase 4 inhibitors (drugs that enhance cAMP signaling, thereby potentiating CREB function) (Bourtchouladze et al. 2003). Second, Alarcón and colleagues showed that both application of phosphodiesterase 4 inhibitors and transgenic overexpression of a dominant active form of CREB partially reverses the L-LTP deficits observed in mice heterozygous for the null mutation of CBP $\left(\mathrm{CBP}^{+/-}\right)$(Alarcón et al. 2004). Together, these findings indicate that at least part of the memory impairments observed in mouse models of RTS may be due to a disruption of CREB-dependent transcription. Moreover, they suggest targeting CREB function may be one therapeutic strategy in the treatment of RTS.

A second therapeutic strategy for the treatment of RTS is suggested by recent results investigating the HAT activity of CBP. By adding acetyl groups to histone proteins, CBP's intrinsic HAT activity is thought to relax the chromatin configuration and facilitate access of the transcriptional machinery to the DNA. Opposing these actions are histone deacetylases (HDACs), enzymes that remove acetyl groups added by HATs. Application of HDAC inhibitors (which presumably boost HAT function) rescues the memory deficits observed in both $\mathrm{CBP}^{+/-}$mice (Alarcón et al. 2004) and transgenic mice that overexpress a mutant form of CBP that lacks HAT activity (Korzus et al. 2004). Taken together, these data suggest that the memory deficits produced by disruption of CBP may be counteracted by enhancing two aspects of CBP function.

Table 1 shows a comparison of the memory and synaptic plasticity phenotypes of the four mouse models of RTS. A number of phenotypic differences between the models are apparent. These disparities may be attributed to differences in gene dosage, the potential contributions of developmental deficits, different background genetics, and the use of different training parameters. Indeed, the finding that additional training often overcomes the memory and LTP deficits induced by various CBP mutations highlights the sensitivity of the CBP phenotype to training conditions. Further investigation is required to determine the precise cause of these differences. However, what is remarkable about Table 1 is that the various mouse models of RTS all produce clear impairments of synaptic and behavioral plasticity, regardless of the method used to disrupt CBP function (conventional knockouts, partial deletions, or transgenic overexpression of dominant-negative forms of $\mathrm{CBP}$ in adult forebrain neurons). Overall, these results provide compelling evidence that CBP is a key molecule in mouse memory and offer important insights into the molecular and cellular basis of human cognition. These findings also highlight the power of mouse models to illuminate novel therapeutic targets for the treatment of cognitive disorders.

\section{References}

Alarcón, J.M., Malleret, G., Touzani, K., Vronskaya, S., Ishii, S., Kandel E.R., and Barco, A. 2004. Chromatin acetylation, memory, and LTP are impaired in $\mathrm{CBP}^{+1-}$ mice: A model for the cognitive deficit in Rubinstein-Taybi syndrome and its amelioration. Neuron 42: 947-959.

Bartsch, D., Ghirardi, M., Skehel, P.A., Karl, K.A., Herder, S.P., Chen, M., Bailey, C.H., and Kandel, E.R. 1995. Aplysia CREB2 represses long-term facilitation: Relief of repression converts transient facilitation into long-term functional and structural change. Cell 83: 979-992.

Bourtchuladze, R., Frenguelli, B., Blendy, J., Cioffi, D., Schutz, G., and Silva, A.J. 1994. Deficient long-term memory in mice with a targeted mutation of the cAMP-responsive element-binding protein. Cell 79: 59-68.

Bourtchouladze, R., Lidge, R., Catapano, R., Stanley, J., Gossweiler, S., Romashko, D., Scott, R., and Tully, T. 2003. A mouse model of Rubinstein-Taybi syndrome: Defective long-term memory is ameliorated by inhibitors of phosphodiesterase 4. Proc. Natl. Acad. Sci. 100: $10518-10522$.

Chrivia, J.C., Kwok, R.P., Lamb, N., Hagiwara, M., Montminy, M.R., and Goodman, R.H. 1993. Phosphorylated CREB binds specifically to the nuclear protein CBP. Nature 365: 855-859.

Dash, P.K., Hochner, B., and Kandel, E.R. 1990. Injection of the cAMP-responsive element into the nucleus of Aplysia sensory neurons blocks long-term facilitation. Nature 345: 718-721.

Davis, H.P. and Squire, L.R. 1984. Protein synthesis and memory: A review. Psychol. Bull. 96: 518-559.

Fanselow, M.S. 2000. Contextual fear, gestalt memories, and the hippocampus. Behav. Brain Res. 110: $73-81$.

Grant, S.G., O'Dell, T.J., Karl, K.A., Stein, P.L., Soriano, P., and Kandel, E.R. 1992. Impaired long-term potentiation, spatial learning, and hippocampal development in fyn mutant mice. Science 258: $1903-1910$.

Josselyn, S.A., Shi, C., Carlezon Jr., W.A., Neve, R.L., Nestler, E.J., and Davis, M. 2001. Long-term memory is facilitated by cAMP response element-binding protein overexpression in the amygdala. J. Neurosci. 21: 2404-2412.

Kalkhoven, E., Roelfsema, J.H., Teunissen, H., den Boer, A., Ariyurek, Y., Zantema, A., and Breuning, M.H. 2003. Loss of CBP acetyltransferase activity by PHD finger mutations in Rubinstein-Taybi syndrome. Hum. Mol. Genet. 12: 441-450.

Kida, S., Josselyn, S.A., de Ortiz, S.P., Kogan, J.H., Chevere, I.,

\section{Learning \& Memory}


Masushige, S., and Silva, A.J. 2002. CREB required for the stability of new and reactivated fear memories. Nat. Neurosci. 5: 348-355.

Korzus, E., Rosenfeld, M.G., and Mayford, M. 2004. CBP histone acetyltransferase activity is a critical component of memory consolidation. Neuron 42: 961-972.

LeDoux, J.E. 2000. Emotion circuits in the brain. Annu. Rev. Neurosci. 23: $155-184$

Matthies, H. 1989. In search of cellular mechanisms of memory. Prog. Neurobiol. 32: 277-349.

McManus, K.J. and Hendzel, M.J. 2001. CBP, a transcriptional coactivator and acetyltransferase. Biochem. Cell. Biol. 79: 253-266.

Oike, Y., Hata, A., Mamiya, T., Kaname, T., Noda, Y., Suzuki, M., Yasue, H., Nabeshima, T., Araki, K., and Yamamura, K. 1999. Truncated CBP protein leads to classical Rubinstein-Taybi syndrome phenotypes in mice: Implications for a dominant-negative mechanism. Hum. Mol. Genet. 8: 387-396.

Petrij, F., Giles, R.H., Dauwerse, H.G., Saris, J.J., Hennekam, R.C., Masuno, M., Tommerup, N., van Ommen, G.J., Goodman, R.H. Peters, D.J., et al. 1995. Rubinstein-Taybi syndrome caused by mutations in the transcriptional co-activator CBP. Nature 376: 348-351.
Pittenger, C., Huang, Y.Y., Paletzki, R.F., Bourtchouladze, R., Scanlin, H., Vronskaya, S., and Kandel, E.R. 2002. Reversible inhibition of CREB/ATF transcription factors in region CA1 of the dorsal hippocampus disrupts hippocampus-dependent spatial memory. Neuron 34: 447-462.

Silva, A.J., Paylor, R., Wehner, J.M., and Tonegawa, S. 1992. Impaired spatial learning in $\alpha$-calcium-calmodulin kinase II mutant mice. Science 257: 206-211.

Tanaka, Y., Naruse, I., Maekawa, T., Masuya, H., Shiroishi, T., and Ishii, S. 1997. Abnormal skeletal patterning in embryos lacking a single Cbp allele: A partial similarity with Rubinstein-Taybi syndrome. Proc. Natl. Acad. Sci. 94: 10215-10220.

Wood, M.A., Kaplan, M.P., Park, A., Blanchard, E.J., Oliveira, A.N.N., Lombardi, T.L., and Abel, T. 2005. Transgenic mice expressing a truncated form of CREB-binding protein (CBP) exhibit deficits in hippocampal synaptic plasticity and memory storage. Learn. Mem. (this issue).

Yin, J.C., Wallach, J.S., Del Vecchio, M., Wilder, E.L., Zhou, H., Quinn, W.G., and Tully, T. 1994. Induction of a dominant negative CREB transgene specifically blocks long-term memory in Drosophila. Cell 79: $49-58$ 


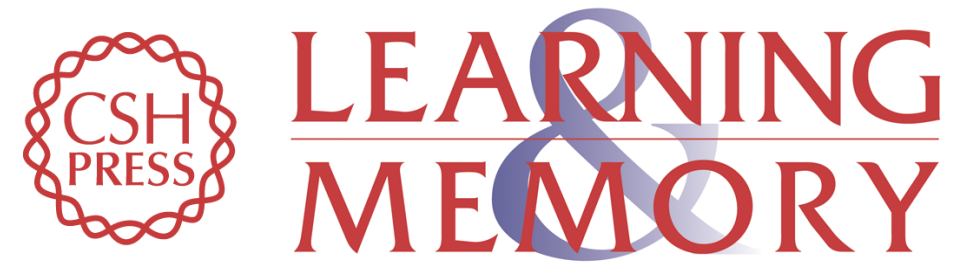

\section{What's right with my mouse model? New insights into the molecular and cellular basis of cognition from mouse models of Rubinstein-Taybi Syndrome}

Sheena A. Josselyn

Learn. Mem. 2005, 12:

Access the most recent version at doi:10.1101//m.93505

References This article cites 22 articles, 5 of which can be accessed free at: http://learnmem.cshlp.org/content/12/2/80.full.html\#ref-list-1

License

Email Alerting

Receive free email alerts when new articles cite this article - sign up in the box at the Service top right corner of the article or click here. 